\title{
Assess the Role of Sonography and MRI in Diagnosing Ovarian Masses
}

\author{
G. Mahender Reddy ${ }^{\oplus 1}$, M. L. Ravindernath ${ }^{\circledR 2}$, S.Snehaja Reddy ${ }^{\circledR 3}$ \\ ${ }^{1}$ Associate Professor, Department of Radiology, Mediciti Institute of Medical Sciences, Ghanpur, Telangana, India, ${ }^{2}$ Professor, Department of Radiology, RVM Institute of \\ Medical Sciences, Mulugu, Siddipet, Telangana, India, ${ }^{3}$ Assistant Professor, Department of Pathology, Mediciti Institute of Medical Sciences, Ghanpur, Telangana, India.
}

\section{Abstract}

Background: In order to conduct appropriate surgical treatments, the characterization of ovarian lesions is of considerable significance and can affect patient care. A multidisciplinary approach based on physical assessment, laboratory tests and imaging techniques includes adequate measurement of the adnexal masses. The aim is to assess the role of Sonography and MR in diagnosing ovarian masses, to study imaging characteristics of ovarian masses on USG and Doppler in correlating these findings with MR features. Subjects and Methods: The present study was carried out in the department of radiodiagnosis to determine the efficacy of sonography and MRI in the diagnosis of ovarian masses. The study group comprised 50 patients with clinically suspected ovarian masses and imaging was carried out on all patients with ovarian masses and imaging was carried out on all patients with ovarian masses. All the masses were evaluated on sonography based on the Sassone scoring system. Morphological analysis was performed for each mass based on wall thickness, inner wall structure, septal structure and echogenicity of mass. The color flow was carried out, subsequently; MRI was carried out for each patient. Radiological diagnosis was confirmed after surgery on histopathological examination. Results: The majority of the patients were in the age group of 31-40 years. The most common symptoms noted were pain in the abdomen. The most common clinical finding was a palpable mass. The application of Sassone sonomorphologic score $>9$ was identified in 8 masses, out of which 7 were malignant and 1 was a benign lesion. The colour flow was detected in 38 out of 50 masses. The presence of flow, type of flow, vessel arrangement, morphology and location were noted and on pulsed Doppler the RI and PI values were calculated. Out of 8 malignant cases, 5 were diagnosed as malignant according to the Caruso score. The overall sensitivity $100 \%$, specificity is $97.6 \%$ and diagnostic accuracy is $98 \%$ of MRI which is higher than that of ultrasound and CDS. Conclusion: We conclude that MRI is a superior diagnostic modality in establishing the diagnosis of ovarian masses.

Keywords: MRI, Ovarian mass, USG

Corresponding Author: M. L. Ravindernath, Professor, Department of Radiology, RVM Institute of Medical Sciences, Mulugu, Siddipet, Telangana, India.

E-mail: ravindernathdr@gmail.com

Received: 22 August 2020

Revised: 26 September 2020

Accepted: 03 October 2020

Published: 30 December 2020

\section{Introduction}

Cervical cancer, endometrial cancer, and ovarian cancer are gynecologic malignancies. Ovarian cancer is the second most serious gynecologic malignancy, but it is the leading cause of death of these diseases and is the fourth leading cause of cancer deaths in women in the United States. ${ }^{[1]}$ The average 5year survival rate has improved little amid medical and clinical advancements in the treatment of women with ovarian cancer. It is projected that about 23,300 people were diagnosed with ovarian cancer in 2002 and that 13,900 people would die of the disease. ${ }^{[2]}$ More than $70 \%$ of all ovarian cancer patients seek care after geographic or remote dissemination of the disease has occurred.

The most prevalent histopathologic form of malignant ovarian tumour (85 percent of cases) is epithelial tumours. Serous, mucinous, endometrioid, clear-cell, and Brenner tumours are subtypes of epithelial tumours. Epithelial tumours are rare before puberty; in the 6th and 7th decades of life, their incidence increases with age and peaks. Serous carcinoma is the most prevalent form of ovarian malignancy (approximately 40 percent of cases). ${ }^{[3]}$

Less than 30 percent of ovarian cancers are already diagnosed at stage I. The poor prognosis of this disease is due to the late stage of manifestation, meaning the average 5-year survival from the point of diagnosis is just 20-30 percent. In comparison, 5-year survival is over 90 percent with stage 1 ovarian cancer. For this cause, the most successful way of increasing the outcome is early diagnosis of ovarian cancer. Ultrasound (US) and magnetic resonance imaging (MRI) provides imaging methods for identification, diagnosis and staging. 
In the initial assessment of potential adnexal masses, ultrasound remains the analysis of choice because it is comparatively cheap, non-invasive, and readily available. It offers excellent morphological detail of the adnexa, enabling mass identification to be enabled. Malignancy is suspected of wall irregularity, thick septations $(>3 \mathrm{~mm})$, papillary projections, solid components and size. Malignant tumours have neovascularity on duplex ultrasound with a distinctive waveform with a low resistive index. (RI 0.4-0.8) and an index of pulsatility smaller than 1 is usually considered suspect of malignancy.

For the diagnosis of ovarian masses, the use of MR imaging requires recognition of morphological characteristics and signal strength characteristics on weighted images of $\mathrm{T} 1 \&$ T2. Morphologically, cystic masses represent benign tumours, while malignancy is closely associated with cystic and stable masses. Benign, borderline malignant and malignant tumours comprise mainly solid masses. Hemorrhagic adnexal masses (like an endometriotic cyst) and cystic teratomas have high signal intensity on T1 weighted images Hemorrhagic adnexal masses (like an endometriotic cyst) and cystic teratomas have high signal intensity on T2 weighted images Low signal intensity in strong masses is suggestive of fibrothecomas and Brenners tumours since on T2 weighted images fibrous tissue generates low signal intensity. Ovarian mass diagnosis with MR imaging incoperates signal amplitude into morphological characteristics.

Gadolinium chelate administration enables internal architecture to be represented and is helpful in separating cystic from solid tumours. Necrosis, papillary projections, solid parts, septations, peritoneal implants, and omental disease are specifically characterised. There have been researching in the West assessing the role of ultrasound and MRI in the identification of ovarian masses, but in Indian literature there has been a shortage of the same, prompting the current review. The aim of this research was to compare the relative precision of ultrasound and MRI imaging in particular ovarian mass diagnosis and, thus, to seek to improve patient prognosis through early detection of malignant disease.

\section{Subjects and Methods}

The study was conducted in the Department of Radiodiagnosis at (in close association with the departments of Obstetrics and Gynecology and Pathology). After clinical evaluation and patient selection Sonography along with Doppler study is done and MRI is performed for further evaluation, histopathology is done in all patients who undergo surgery patient with metallic implants in situ was also excluded. Prospectively study for a period of two years using Sonography and MR in diagnosing ovarian masses from 01-05-2017 to 01-05-2019

\section{Inclusion Criteria:}

All female patients, of all age groups attending gynecology OPD with ovarian masses

Patients who come for Sonography in the Radiology department in suspected ovarian masses

\section{Exclusion Criteria:}

Patients in whom MR is contraindicated

Patients who are not willing for further evaluation in our hospital

\section{Ultrasonography:}

Transabdominal real-time greyscale ultrasound was performed in all patients as a baseline investigation with a $2-7 \mathrm{MHz}$ curvilinear 2D abdominal transducer on Ultrasound machines used are Toshiba core-vision Pro, E'saotes My Lab 40 and E'saotes My Lab 50. All the machines had Transabdominal and Transvaginal probes with a frequency of 3.5-12 MHZ, through the distended bladder using coupling gel for a good skin transducer contact. The pelvis was assessed for any ovarian lesion that was further evaluated for its size, extent, echopattern\& internal structure. The abdomen was routinely scanned for the presence of ascites, lymphadenopathy, peritoneal deposits, hydronephrosis, pleural effusion, metastatic deposits in abdominal organs or any other abdominal pathology.

Transvaginal (or endovaginal) ultrasound was performed with 5-9 $\mathrm{MHz}$ real-time interactivity endovaginal transducer on Toshiba core-vision Pro, E'saotes My Lab 50 and E'saotes My Lab 40. All the machines had Transabdominal and Transvaginal probes with a frequency of 3.5-12 MHZ.

Morphological evaluation of the ovarian mass was performed in each case according to Sassones criteria and a score was assigned to each mass. ${ }^{[4]}$ The total score ranged from 4-15 with a score of 9 or greater being considered suggestive of malignancy.

\section{Color doppler sonography:}

Doppler evaluation was performed using. Color flow imaging and spectral waveform analysis were done for all patients with ovarian masses. The color and pulsed doppler parameters including wall filter, gate width, gain and velocity scale were optimized for each case. When color signals were detected flow results were recorded as being present. The flow was characterized as normal (fine branching vessels, peripheral flow, no evidence of hot spots or aliasing) or as increased (dilated prominent vessels, central flow, and evidence of hot spots or aliasing).

Using pulsed doppler, a spectral waveform was obtained. Three uniform consecutive pulsebeats were analyzed and the resulting values were averaged. The waveform was analyzed for the following parameters:

Resistance index $(\mathrm{RI})=\mathrm{PSV}-\mathrm{EDV} / \mathrm{PSV}$ 
Pulsatility index $(\mathrm{PI})=\mathrm{PSV}-\mathrm{EDV} / \mathrm{MFV}$

Where, PSV= peak systolic velocity, $\mathrm{EDV}=$ end-diastolic velocity, $\mathrm{MFV}=$ mean flow velocity.

The lowest RI and PI were detected and the maximum PSV was used for analysis. The doppler findings were considered as being suggestive of malignancy when

$\mathrm{RI}</=0.4$

$\mathrm{PI}</=1$

$\mathrm{PSV}>/=15 \mathrm{cms} / \mathrm{sec}$.

Lesions with flow detectable on color doppler study were evaluated on the basis of the vascular scoring system as described by Caruso et al. ${ }^{[5]}$

\section{Results}

The study comprised of 50 patients who were evaluated clinically and then subjected to USG examination. Transabdominal sonography (TAS) was done in all 50 patients and transvaginal sonography was done whenever necessary in those patients and transvaginal sonography was done whenever necessary in those patients with prior consent. All the ovarian masses detected on ultrasound were subjected to color Doppler sonography. Those masses with flow on CDS were further evaluated by pulsed Doppler.

MRI imaging was subsequently performed for all the cases. The imaging characteristics of these ovarian masses on USG, CDS and MRI were determined and each lesion was evaluated to be benign or malignant. The findings were further correlated with histopathology post-surgery. Of the 50 patients with ovarian masses, 42 patients $(84 \%)$ were confirmed to have benign lesions and 8 patients $(16 \%)$ had malignant masses.

The patient's age ranged from 12-66 years. The maximum age preponderance was noted in the $31-40$ years age group (44\%) followed by the $21-30$ years age group (20\%). The average size of a tumor in cases is $8.19+3.35 \mathrm{cms}$.

Among the detected masses a maximum number of masses turned out to be Benign. serous cystadenoma, (16\%) Dermoid $(16 \%)$.

Each lesion is analysed for shape, content, presence of enhancing solid component, the thickness of the wall and septa, presence of irregularity or nodule on the wall and septa, presence of irregularity or nodule on the wall and septa and the presence of necrosis. The presence of significant ascites, lymphadenopathy, pelvi sidewall involvement and peritoneal implants was also noted in ovarian masses. 11 out of 50 masses had irregular shape out of which 6 masses were malignant and 5 masses were benign.

MRI has $100 \%$ sensitivity and $97.6 \%$ specificity, MRI in total has $98 \%$ diagnostic accuracy.
Discussion:

The study included 50 patients out of which 42 patients had benign masses \& 8 patients had malignant masses. The majority of the patients had benign lesions and it universally acknowledged that benign ovarian lesions greatly outnumber the malignant ones. Most of the patients with benign ovarian masses were premenopausal. The maximum age preponderance was noted in the 31-40 years age group. The maximum percentage of masses was on the right side. Most of the patients presented with more than 1 symptom. The commonest symptoms at presentation were pain abdomen, lump abdomen and distention. The average duration of duration of symptoms was 1-2 months and all the patients with malignant neoplasm's presented within 4 months of the onset of symptoms.

CA 125 levels were done in all 5 patients with malignant masses and were raised in 3 of them (60\%). CA 125 levels may be elevated in first-trimester pregnancy, liver cirrhosis, PID, liver diseases and pancreatitis besides being raised in ovarian malignancy. This group consisted of 6 patients. Out of 6 patients 4 were premenopausal patients and 2 were postmenopausal, and 3 were on the right side 2 was on the left side and 1 was bilateral, 2 patients had Caruso score $>5$ and 4 patients $<5$. On the Sassone score, all patients had less than 9. MRI pelvis revealed multiple cystic lesions and 1 bilateral cystic lesion in adnexal inseparable from the ovaries with the hemorrhagic signal. MRI diagnosis was bilateral cystadenomas with chochalate cyst which turned out to be mucinous cysts chochalate cyst on the number of septations was more in mucinous cystadenoma than in serous cystadenoma. Some case has thin septation $\mathrm{s}$ and solid component. All the patients underwent surgery and the histopathological report revealed mucinous cystadenomas. Lymph nodes were noted in one case of mucinous cystadenomas. These my findings are in accordance with Fried AM et al and Jung SE et al. ${ }^{[6,7]}$

Serous cystadenoma includes 8 patients out of 8 patients 3 were on the right side and 5 were on the left side with one bilateral case. The patients aged ranged from $24-45$ years all the patients presented with pain and a lump in the abdomen. Ultrasound revealed cystic lesions with septations noted in all cases one patient had Caruso score $>5$ and all the patients had a Sassone score $<9$. In one case ascites were present and capillaries $>3 \mathrm{~mm}$ noted in one case and low echogenic contents. MRI revealed all cases cystic lesions with septations and one single case showed ascites and papillary projections were noted in one case. The imaging findings include signal intensity is similar to that of water with high signal intensity on T2 WT by Bennet GL et al. ${ }^{[8]}$ Small papillary projections may arise from the cyst wall of serous cystadenoma is approximately $20 \%$ by Bazot $\mathrm{M}$ et al. ${ }^{[9]}$ 


\begin{tabular}{lll}
\hline \multicolumn{2}{l}{ Table 1: Age-wise distribution of ovarian masses } \\
\hline Age group (in yrs) & Number of patients & Percentages \\
\hline $11-20$ & 4 & 8 \\
$21-30$ & 10 & 20 \\
$31-40$ & 22 & 44 \\
$41-50$ & 8 & 16 \\
$51-60$ & 3 & 6 \\
$61-70$ & 3 & 6 \\
\hline Total & 50 & 100 \\
Size (in cms) & & \\
\hline $1-5$ & 13 & 26 \\
$6-10$ & 28 & 56 \\
$11-15$ & 7 & 14 \\
$>15$ & 2 & 4 \\
\hline Total & 50 & 100 \\
Mean + SD & $8.19+3.35 \mathrm{cms}$ & \\
\hline
\end{tabular}

Table 2: Performance of sonomorphic analysis (by Sasssone scoring) and Color Doppler Sonography (by Caruso scoring)

\begin{tabular}{|c|c|c|c|c|c|}
\hline & Sens itivity & Specificity & PPV & NPV & Diagnostic accuracy \\
\hline Sassone Score & $87.5 \%$ & $97.62 \%$ & $87.5 \%$ & $97.62 \%$ & $96 \%$ \\
\hline \multicolumn{6}{|c|}{ Color and pulsed Doppler Sonography } \\
\hline Increase flow & 62.5 & 76.67 & 41.67 & 88.46 & 73.68 \\
\hline $\begin{array}{l}\text { Random arrangement } \\
\text { of vessels }\end{array}$ & 75 & 76.67 & 46.15 & 92 & 76.31 \\
\hline $\mathrm{RI}</ 0.4 \& \mathrm{PSV}>15$ & 75 & 56.67 & 31.58 & 89.47 & 60.52 \\
\hline $\mathrm{PI}</=1$ & 75 & 56.67 & 31.58 & 89.47 & 60.52 \\
\hline $\begin{array}{l}\text { Abnormal vessel mor- } \\
\text { phology }\end{array}$ & 87.5 & 76.67 & 50 & 95.83 & 78.9 \\
\hline
\end{tabular}

The hemorrhagic cyst group includes 6 patients, the age group in this varied from $20-45$ years. Out of the 6 masses, 4 were on the right side and 2 were on the left side.

All the patients had Sassone score $<9$ and Caruso score $<5$, one patient had mixed echogenicity and one patient had low echogenicity lesion. On MRI the entire lesion showed high signal intensity on T1 and T2weighted images. All the patients underwent surgery and the histopathological report confirmed the diagnosis. It usually has a smooth posterior wall and shows posterior acoustic enhancement indicating the cystic nature of the lesion diffuse low-level echoes. A reticular network of netlike strands is occasionally seen by Patel MDet al. ${ }^{[6]}$

On Color Doppler scan the absence of vascularity within the solid portions consisting of clot supports the diagnosis of hemorrhage.

On MRI, they have relatively high signal intensity on T1weighted images and intermediate to high signal intensity on
T2-weighted images. Fat-saturated techniques are useful in differentiating between hemorrhage and fat by Stevens SK et al, ${ }^{[7]}$ Kier R et al. ${ }^{[10]}$

Corpus leuthal cyst group consists of one patient aged 16 years who presented with tenderness in the left lower abdomen. Clinical examination revealed a left adnexal mass with a bulky uterus. Ultrasound revealed a complex left ovarian mass. On ultrasound it was well defined complex cystic lesion, with peripheral vascularity. On MRI pelvis high signal intensity on T1-weighted images and intermediate to high signal intensity on T2-weighted owing to hemorrhagic contents suggestive of left corpus leuthal cyst with wall irregularity the patient underwent surgery and the histopathological report revealed a diagnosis of corpus luteal cyst with omental involvement. These my findings are in accordance with Out water EK et al. ${ }^{[11]}$ 


\begin{tabular}{|c|c|c|c|c|}
\hline Final Diagnosis & Number of cases & Right & Left & bilateral \\
\hline $\begin{array}{l}\text { Benign serous cystade- } \\
\text { noma }\end{array}$ & $8(16 \%)$ & $3(6 \%)$ & $5(10 \%)$ & $1(2 \%)$ \\
\hline Brenner tumour & $1(2 \%)$ & $1(2 \%)$ & $0(0 \%)$ & $0(0 \%)$ \\
\hline Corpous luteal cyst & $1(2 \%)$ & $0(0 \%)$ & $1(2 \%)$ & $0(0 \%)$ \\
\hline Dermoid & $8(16 \%)$ & $5(10 \%)$ & $3(6 \%)$ & $0(0 \%)$ \\
\hline Endometriosis & $4(8 \%)$ & 3 & $1(2 \%)$ & $0(0 \%)$ \\
\hline Granulosa cell tumor & $1(2 \%)$ & $1(2 \%)$ & $0(0 \%)$ & $0(0 \%)$ \\
\hline Haemorrhagic cyst & $6(12 \%)$ & $4(8 \%)$ & $2(4 \%)$ & $0(0 \%)$ \\
\hline Immature terotoma & $1(2 \%)$ & $1(2 \%)$ & $0(0 \%)$ & $0(0 \%)$ \\
\hline $\begin{array}{l}\text { Mucinous cystade- } \\
\text { noma }\end{array}$ & $6(12 \%)$ & $3(6 \%)$ & $2(4 \%)$ & $1(2 \%)$ \\
\hline Ovarian torsion & $2(4 \%)$ & $2(4 \%)$ & $0(0 \%)$ & $0(0 \%)$ \\
\hline $\begin{array}{l}\text { Serous adenocarci- } \\
\text { noma }\end{array}$ & $5(10 \%)$ & $3(6 \%)$ & $2(4 \%)$ & $0(0 \%)$ \\
\hline Simple ovarian cyst & $6(12 \%)$ & $4(8 \%)$ & $2(4 \%)$ & $0(0 \%)$ \\
\hline
\end{tabular}

\begin{tabular}{|c|c|c|c|c|c|}
\hline Criterion & Sensitivity & Snecificity & PPV & NPV & Diaonostic accuracy \\
\hline Shape & 75 & 88 & 54.5 & 94.8 & $86 \%$ \\
\hline Sloid component & 62.5 & 80.9 & 38.4 & 91.8 & $78 \%$ \\
\hline Wall thickness $>3$ & 50 & 69 & 23.5 & 87.8 & $66 \%$ \\
\hline $\begin{array}{l}\text { Wall irregularity/ } \\
\text { nodule }\end{array}$ & 62.5 & 71.4 & 29.4 & 90.9 & $70 \%$ \\
\hline $\begin{array}{l}\text { Septal thick- } \\
\text { ness }>3 \mathrm{~mm}\end{array}$ & 37.5 & 83.3 & 30 & 87.5 & $76 \%$ \\
\hline Necrosis & 50 & 88.1 & 44.4 & 90.2 & $82 \%$ \\
\hline $\begin{array}{l}\text { Enhancement of } \\
\text { solid component }\end{array}$ & 87.5 & 95.6 & 77.7 & 97.5 & $94 \%$ \\
\hline $\begin{array}{l}\text { Pelvic } \\
\text { organ/Sidewall } \\
\text { involvement }\end{array}$ & 37.5 & 97.6 & 75 & 89.1 & $88 \%$ \\
\hline Lymphadenopathy & 62.5 & 90.4 & 55.5 & 92.6 & $86 \%$ \\
\hline $\begin{array}{l}\text { Significant } \\
\text { ascites }\end{array}$ & 50 & 97.6 & 80 & 91.1 & $96 \%$ \\
\hline
\end{tabular}

Granulosa Cell Tumor group consisted of a 47 years old postmenopausal female who had come with complaints of pain lower abdomen, pain and loss of weight. Ultrasound revealed right ovarian mixed echogenity predominantly solid mass Sassone score was 12, Color flow study had revealed the presence of blood flow with abnormal and randomly arranged vessels Caruso score was $>5$. Contrast MRI pelvis had revealed a large heterogeneous lesion with a predominantly solid and central necrotic area. Enhancement of walls and solid areas were noted the patient underwent surgery and the histopathological report revealed a diagnosis of granulosa cell tumor in the right ovary. There are enlarged pelvic and paraaortic lymphnodes noted. Imaging findings vary considerably from entirely cystic to completely solid ovarian lesions as seen by Jung SE et al. ${ }^{[12]}$ The most common type is predominantly sponge-like, cystic, multilocular mass or a cystic and solid tumor with blood clots as described by Kim SH et al. ${ }^{[13]}$ 


\begin{tabular}{llll}
\hline Table 5: MRI Diagnosis & & & \\
\hline MRI & Final Diagnosis & Final Diagnosis & Total score \\
\hline Malignant (number of cases) & 8 & 1 & 9 \\
Benign (number of cases) & 0 & 41 & 41 \\
\hline Total number (number of cases) & 8 & 42 & 50 \\
\hline Sensitivity & $100 \%$ & & \\
Specificity & $97.6 \%$ & & \\
Positive predictive value & $88.8 \%$ & & \\
\hline Negative predictive value & 1 & & \\
Diagnostic accuracy & $98 \%$ & & \\
\hline
\end{tabular}

Immature Teratoma group consisted of a 26 years old young patient who had come with complaints of and pain lower abdomen. The clinical examination had revealed a rightsided ovarian mass. Ultrasound pelvis had revealed a mixed echogenicity lesion with a Sassone score of 12 and a Caruso score $<5$. MRI pelvis revealed a large well-defined enhancing lesion associated with ascites. A diagnosis of cystadenoma was given. The patient underwent right salpingoovariotomy and histopathological from the postoperative sample revealed immature teratoma grade 3 right ovary. Immature teratomas present in imaging as unilateral, primarily solid or mixed solid and cystic tumours typically greater than $10 \mathrm{~cm}$ in diameter are the products of Bazot $\mathrm{M}$ et al. ${ }^{[9]}$ Unlike dermoids, immature teratomas are normally solid cyst-containing tumours, and calcification is not morally placed but within the mass.

The transitional cell tumor group consisted of a 62-year-old postmenopausal patient with complaints of pain and lump in the abdomen. On clinical examination, there was palpable mass arising from the pelvis with restricted mobility and firm inconsistency. On ultrasound there mixed echogenicity lesion with Sassone score $<9$ and Caruso score $<5$, with complex mass was kept as a probable diagnosis. This is in line with Kurman RJ (Ed.) et al. ${ }^{[14]}$

The ovarian torsion group consisted of 2 patients one patient aged 12 years and the other patient aged 52 years. Ultrasound of the first patient revealed an enlarged ovary measuring about $5 \mathrm{cms}$ on the right side. The other patient Ultrasound had revealed a large cystic lesion measuring about $9.1 \mathrm{cms}$ on the anterior surface of the uterus on the right side. Similar findings are noted by Graif $\mathrm{M}$ et al. ${ }^{[15]} \mathrm{CDS}$ revealed it to be an avascular lesion in both patients. MRI of the first patient revealed a twisted and enlarged ovary on the right side and other MRI pelvis revealed a large cystic lesion with septae anterosuperior to the uterus. Vijayaraghavan SB et al also noted the same findings. ${ }^{[16]}$

Simple ovarian cyst: This group includes 6 patients (4 patients on the right side and two on the left side). Out of 6 patients 5 were pre-menopausal and 1 was a postmenopausal patient.
All patients had a Sassone score $<9$ and Caruso $<5$, only one patient had a solid component noted within the lesion. On MRI T2hyperintensity was noted in all 4 cysts. These findings are in accordance with Out water EK et al. ${ }^{[11]}$ All the patients underwent surgery and the diagnosis was confirmed on histopathology. It is rare for a simple cyst to be malignant and this seems to occur only with large cysts.

The dermoid group consists of 8 patients, 5 on the right side and 3 were on the left side. Out of 8 patients 7 patients were premenopausal and 1 was post-menopausal. All the patients and had a Sassone score $<9$ and a Caruso score $<5$. There was a lymph node noted in two cases. Plain X-Ray revealed calcification and rudimentary tooth in 1 case. USG was done in all the 8 patients and it revealed Hyperechoic components in 1 masses, a solid component was noted in 5 cases and with mixed echogenicity in 6 cases dermoid plugs in 1 case hyperechoic lines and dots in 2 masses, echogenic foci with dense shadowing suggestive of calcification in 2 masses. The various USG features have been described by Sheth $\mathrm{S}$ et al. ${ }^{[17]}$ On MRI, fat was detected in 6 out of the 7 masses by application of fat suppression technique. The lesions were hyperintense on T1WI and of intermediate intensity on T2WI with loss of signal on the fat-saturated images. The other features seen on MRI include floating debris, layering, identification of a dermoid plug and signal voids suggestive of calcification. Similar findings have been described by Stevens et al. ${ }^{[4]}$ Post-contrast enhancement of the solid component was noted in 2 cases to rule out malignancy.

The endometriosis group includes 4 patients 3 on the right side and 1 on the left side, the patient age ranged from $24-35$. All the patients had a Sassone score $<5$ and only one patient had Caruso score $>5$. On ultrasound there are cystic masses with low-level moving internal echoes. Fluid level was noted in 2 cases in our study. There were no septations noted in our study. On MRI these masses were hyperintense on T1WI with no loss of signal on fat-suppressed sequences. On T2WI these lesions were hypointense and exhibited signs of shading and layering (characteristic of endometriomas as described by Togashi et 
al. ${ }^{[18]}$

Mucinous cystadenocarcinoma group includes 1 patient in the pre-menopausal age group the chief complaints were pain in the abdomen and lump in the abdomen. On ultrasound it revealed a large multiloculated cystic lesion with thick septations and low echogenic material. Sassone score was 8 and Caruso score was $>5$. On MRI, the lesions appeared hypointense on TIWI and hyperintense on T2WI with the enhancement of wall septae and solid component. Free fluid was noted in the pelvis.

Serous cystadenocarcinoma group consisted of 5 patients of which 3 were premenopausal and 2 were postmenopausal. The patient presented with a lump and pain in the lower abdomen. Ultrasound abdomen had revealed multiloculated cystic masses with echogenic material in all the 2 patients, mixed echogenicity in 2 patients and 1 with hypoechoic lesion. Sassone score was $>9$ in all the 5 masses and Caruso score was $>5$ in 4 of them and one case revealed, 5 septations were noted in 4 cases, there was also ascites noted in 2 cases and lymph nodes in 4 cases On MRI, the lesions appeared hypointense on TIWI and hyperintense on T2WI with wall irregularities, septae and solid component.

Morphology of ovarian masses as assessed by grey-scale ultrasound was studied using the scoring system described by Sassone et al. ${ }^{[4]}$ In our series 8 out of 50 masses $(16 \%)$ had Sassone score $>9$ out of which 1 was benign mass and 7 were malignant masses .42 masses $(84 \%$ ) had score $<9$, out of which 1 was malignant and 41 were benign. The sensitivity was 87.5 , lower than $100 \%$ observed by Sassone et al, ${ }^{[4]}$ as 1 mucinous cystadenocarcinoma had non-suspicious morphology. In my study only one benign lesion had score $>9$ resulting in high specificity.

CDS was performed for each mass following grayscale evaluation. Each lesion was analyzed for the presence of flow, increased flow, vessel location, arrangement and morphology. The intratumoral RI, PI and PSV values were observed. The sensitivity rate of $\mathrm{RI}</=0.4$ in the detection of malignant lesions was $75 \%$. It is higher than $37.5 \%$ reported by Schneider et al. ${ }^{[19]}$ The specificity rate of $56.67 \%$ is lower than $97.1 \%$ reported by Kurjak et al. ${ }^{[20]}$

A cutoff value of $</=1.0$ for PI had a sensitivity of $75 \%$ which was lower than $94 \%$ observed by other authors. The application of Caruso sore identified 6masses with the suspicious vascular score $>/=5$. The sensitivity and specificity using the vascular score were respectively $75 \%$ and $90.4 \%$ as compared to $100 \%$ and $92 \%$ calculated by Caruso et al. ${ }^{[5]}$ All the ovarian masses were detected on ultrasound and were evaluated by CDS followed by MRI evaluation. An irregular shape had a sensitivity of $75 \%$ and a high specificity of $88.1 \%$ in the prediction of malignancy. The presence of a solid component had a sensitivity of $62.5 \%$, a specificity of
$80.9 \%$ PPV of $38.4 \%$. However enhancing solid component had a sensitivity of $87.5 \%$, a specificity of $95.5 \%$, a PPV of $77.7 \%$ and diagnostic accuracy of $94 \%$. Wall thickness $>3 \mathrm{~mm}$ as an indicator of malignancy had a sensitivity of $50 \%$ higher than $35.2 \%$ observed by authors. Septal thickness $>3 \mathrm{~mm}$ had a low sensitivity of $37.5 \%$ and a high specificity of $83.3 \%$. Identification of necrosis within the lesion had a low sensitivity of $50 \%$. The presence of peritoneal implants or pelvic organ or sidewall involvement was highly specific (97\%) for malignant ovarian masses. Sohaib et al, ${ }^{[21]}$ have observed comparable findings of low sensitivity and $100 \%$ specificity. Lymphadenopathy as an indicator of malignancy had a sensitivity of $62.5 \%$ and a specificity of $90.4 \%$ as compared to a sensitivity of $31.3 \%$ and specificity of $96.7 \%$ in a study by Sohaib et al. ${ }^{[21]}$ The presence of significant ascites as a predictor of malignancy had a specificity of $97.6 \%$ higher than $96.5 \%$ reported by Sohaib et al. ${ }^{[21]}$

Table 6: Comparative analysis of MRI in the prediction of malignancy by various authors

\begin{tabular}{|c|c|c|c|}
\hline $\begin{array}{ll}\text { Study } & \text { By } \\
\text { Authors } & \end{array}$ & $\begin{array}{l}\text { Sensitivity } \\
(\%)\end{array}$ & $\begin{array}{l}\text { Specificity } \\
\text { (\%) }\end{array}$ & $\begin{array}{l}\text { Diagnostic } \\
\text { accu- } \\
\text { racy }(\%)\end{array}$ \\
\hline $\begin{array}{l}\text { Hricak } \\
\mathrm{al},{ }^{[22]}\end{array}$ & 95 & 79 & 93 \\
\hline Huber et al, [23] & 95 & 87 & 89 \\
\hline $\begin{array}{l}\text { Sohaib et } \\
\text { al, }{ }^{21]}\end{array}$ & 96.6 & 83.7 & 88.9 \\
\hline $\begin{array}{l}\text { Marc Bazotet } \\
\mathrm{al},{ }^{[24]}\end{array}$ & 84.8 & 45.6 & 88.8 \\
\hline $\begin{array}{l}\text { Booth SJ et } \\
\text { al, }[25]\end{array}$ & 92 & 76 & 84 \\
\hline Present study & 100 & 97.6 & 98 \\
\hline
\end{tabular}

The findings in the present series are similar to those seen by most of the previous authors.

Table 7: Performance of sonomorphic analysis (by Sasssone scoring), Color Doppler Sonography (by Caruso scoring) and MRI (by Steven criteria) in the prediction of malignancy.

\begin{tabular}{llllll}
\hline & Sensitivit & Specific & PPV & NPV & $\begin{array}{l}\text { Diagnostic } \\
\text { Accu- } \\
\text { racy }\end{array}$ \\
\hline Sonom & 87.5 & 97.6 & 87.5 & 97.6 & $96 \%$ \\
CDS & 75 & 90.4 & 60 & 95 & $88 \%$ \\
MRI & 100 & 97.6 & 88.8 & 1 & $98 \%$ \\
\hline
\end{tabular}

Thus, MRI had a high sensitivity, specificity and diagnostic accuracy in the prediction of malignant ovarian neoplasms. Sohaib et al 2003 also found MRI TO BE MORE specific and accurate than USG and CDS combined for characterization of 
ovarian masses. Though USG is a sensitive modality in the detection of ovarian disease, it is not very specific

\section{Conclusion}

Ovarian massess are the most common in the age group of 31-40 years and the diagnosing modalities available are sonomorphology, clour Doppler and MRI. Sonography due to its cost and easy availability is the initial modality of choice in etecting the ovarian mass. a combined morphological and vascular imaging allowed better characterization of the mass and prediction of malignancy. Hence using a combined color Doppler sonomorphologic assessment as the first imaging modality of ovarian masses appears to be a cost-effective method of diagnosing malignancy.

However, MRI due to its multiplanar capability, superior softtissue contrast and better definition of the internal architecture of the lesion allowed accurate characterization and localization of ovarian masses.

The use of contrast-enhanced MRI improves the diagnosis of malignancy in complex ovarian masses and should be used in lesions that are indeterminate or inadequately localized by combined color Doppler sonography. Here we conclude that MRI is a superior diagnostic modality in establishing the diagnosis of ovarian masses.

\section{References}

1. Landis SH, Murray T, Bolden S, Wingo PA. Cancer statistics, 1998. CA Cancer J Clin. 1998;48(1):6-29. Available from: https://dx.doi.org/10.3322/canjclin.48.1.6.

2. Jemal A, Thomas A, Murray T, Thun M. Cancer statistics, 2002. CA Cancer J Clin. 1997;52(1):23-47. Available from: https://doi.org/10.3322/canjclin.52.1.23.

3. Sharma M, Khangar B, Mallya V, Khurana N, Gupta S. Coexisting Brenner Tumor and Endometrial Carcinoma. J Midlife Health. 2017;8(2):89-91. Available from: https://dx. doi.org/10.4103/jmh.JMH_3_17.

4. Sassone AM, Timor-Tritsch IE, Artner A, Westhoff C, Warren WB. Transvaginal sonographic characterization of ovarian disease: evaluation of a new scoring system to predict ovarian malignancy. Obste Gynecol. 1991;78(1):70-76.

5. Caruso A, Caforio L, Testa AC, Ciampelli M, Panici PB, Mancuso S. Transvaginal Color Doppler Ultrasonography in the Presurgical Characterization of Adnexal Masses. Gynecol Oncol. 1996;63(2):184-191. Available from: https://dx.doi. org/10.1006/gyno.1996.0304.

6. Patel MD, Feldstein VA, Chen DC, Lipson SD, Filly RA. Endometriomas: Diagnostic Performance of US. Radiology. 1999;210(3):739-745. Available from: https://dx.doi.org/10. 1148/radiology.210.3.r99fe61739.

7. Stevens SK, Hricak H, Stern JL. Ovarian lesions: detection and characterization with gadolinium-enhanced MR imaging at 1.5 T. Radiology. 1991;181(2):481-488. Available from: https://dx.doi.org/10.1148/radiology.181.2.1924792.

8. Bennett GL, Slywotzky CM, Giovanniello G. Gynecologic Causes of Acute Pelvic Pain: Spectrum of CT Findings. Radiographics. 2002;22(4):785-801. Available from: https: //dx.doi.org/10.1148/radiographics.22.4.g02j118785.

9. Bazot M, Nassar-Slaba J, Thomassin-Naggara I, Cortez A, Uzan S, Daraï E. MRI compared with intra operative frozensection examination for the diagnosis of adnexal tumors; corelation with final histology. Eur Radiol. 2006;16(12):26872699. Available from: https://doi.org/10.1007/s00330-0060163-z.

10. Kier R, Smith RC, McCarthy SM. Value of lipid- and water-suppression MR images in distinguishing between blood and lipid within ovarian masses. Am J Roentgenol. 1992;158(2):321-325. Available from: https://dx.doi.org/10. 2214/ajr.158.2.1729791.

11. Outwater EK, Mitchell DG. Normal ovaries and functional cysts: MR appearance. Radiology . 1996;198(2):397402. Available from: https://doi.org/10.1148/radiology.198.2. 8596839.

12. Jung SE, Lee JM, Rha SE, Byun JY, Jung JI, Hahn ST. CT and MRI of ovarian masses with emphasis on differential diagnosis. Radiographics. 2002;22(6):1305-1325. Available from: https: //doi.org/10.1148/rg.226025033.

13. Kim JS, Woo SK, Suh SJ. Ultrasonographic diagnosis of tube masses, emphasis on detection of the ovary. J Korean Soc Med US. 1990;9:136-144.

14. Kurman RJ. Springer-Verlag; 1994.

15. Graif M, Shalev J, Strauss S, Engelberg S, Mashiach S, Itzchak Y. Torsion of the ovary: sonographic features. Am J Roentgenol. 1984;143(6):1331-1334. Available from: https: //dx.doi.org/10.2214/ajr.143.6.1331.

16. Vijayaraghavan SB. Sonographic Whirlpool Sign in Ovarian Torsion. J Ultrasound Med. 2004;23(12):1643-1649. Available from: https://doi.org/10.7863/jum.2004.23.12.1643.

17. Sheth S, Fishman EK, Buck JL, Hamper UM, Sanders RC. The variable sonographic appearances of ovarian teratomas: correlation with CT. Am J Roentgenol. 1985;151:331-335. Available from: https://doi.org/10.2214/ajr.151.2.331.

18. Togashi K, Nishimura K, Kimura I, Tsuda Y, Yamashita K, Shibata T, et al. Endometrial cysts: diagnosis with MR imaging. Radiology. 1991;180(1):73-78. Available from: https://dx.doi. org/10.1148/radiology.180.1.2052726.

19. Schneider VL, Schneider A, Reed KL, Hatch KD. Comparison of Doppler with two-dimensional sonography and CA 125 for prediction of malignancy of pelvic masses. Obstet Gynecol. 1993;81:983-988.

20. Kurjak A, Predanic M, Kupesic-Urek S, Jukic S. Transvaginal Color and Pulsed Doppler Assessment of Adnexal Tumor Vascularity. Gynecol Oncol. 1993;50(1):3-9. Available from: https://dx.doi.org/10.1006/gyno.1993.1154.

21. Rockall AG, Meroni R, Sohaib SA, Reynolds K, AlexanderSefre F, Shepherd JH, et al. Evaluation of endometrial carcinoma on magnetic resonance imaging. Int $\mathrm{J}$ Gynecol Cancer . 2007;17(1):188-196. Available from: https://dx.doi. org/10.1111/j.1525-1438.2007.00805.x.

22. Hricak H, Chen M, Coakley FV, Kinkel K, Yu KK, Sica G, et al. Complex Adnexal Masses: Detection and Character- 
ization with MR Imaging-Multivariate Analysis. Radiology. 2000;214(1):39-46. Available from: https://dx.doi.org/10. 1148/radiology.214.1.r00ja3939.

23. Huber S, Wagner M, Zuna I, Medl M, Czembirek H, Delorme S. Locally advanced breast carcinoma: evaluation of mammography in the prediction of residual disease after induction chemotherapy. Anticancer Res. 2000;20(1B):553558.

24. Bazot M, Darai E, Hourani R, Thomassin I, Cortez A, Uzan $\mathrm{S}$, et al. Deep Pelvic Endometriosis: MR Imaging for Diagnosis and Prediction of Extension of Disease. Radiology. 2004;232(2):379-389. Available from: https://dx.doi.org/10. 1148/radiol.2322030762.

25. Booth SJ, Pickles MD, Turnbull LW. In vivo magnetic resonance spectroscopy of gynaecological tumours at 3.0 Tesla. BJOG. 2009;116(2):300-303. Available from: https://doi.org/ 10.1111/j.1471-0528.2008.02007.x.

Copyright: (C) the author(s), 2020. It is an open-access article distributed under the terms of the Creative Commons Attribution License (CC BY 4.0), which permits authors to retain ownership of the copyright for their content, and allow anyone to download, reuse, reprint, modify, distribute and/or copy the content as long as the original authors and source are cited.

How to cite this article: Reddy GM, Ravindernath ML, Reddy SS. Assess the Role of Sonography and MRI in Diagnosing Ovarian Masses. Asian J. Med. Radiol. Res. 2020;8(2):41-49.

DOI: dx.doi.org/10.47009/ajmrr.2020.8.2.7

Source of Support: Nil, Conflict of Interest: None declared. 